Estudios Constitucionales, Año 8, No 1, 2010, pp. 425 - 442.

ISSN 0718-0195

Centro de Estudios Constitucionales de Chile Universidad de Talca

"La aplicación por los tribunales chilenos del derecho internacional de los derechos humanos"

Miguel Ángel Fernández González

\title{
LA APLICACIÓN POR LOS TRIBUNALES CHILENOS DEL DERECHO INTERNACIONAL DE LOS DERECHOS HUMANOS
}

\author{
The Application of International \\ Human Rights Law by Chilean Tribunals
}

\author{
Miguel Ángel Fernández González* \\ Profesor de Derecho Constitucional en la Universidad Católica, \\ en la Universidad de Chile y en la Universidad de los Andes \\ mafernande@cb.cl
}

RESUMEN: La aplicación del Derecho Internacional de los Derechos Humanos por los tribunales chilenos ha ido evolucionando. La jurisprudencia nacional ha ido experimentando un cambio en cuanto a la aplicación de los tratados internacionales de derechos humanos. En este trabajo se examinan casos tanto ante la justicia ordinaria como ante la justicia constitucional, donde se intenta demostrar el alcance cada vez mayor que posee el Derecho Internacional de los derechos humanos.

ABSTRACT: The application of International Human Rights Law by the Chilean tribunals has been evolving. The national case law has experienced a change as to the application of human rights international treaties. This paper examines cases both before the ordinary justice and the constitutional justice, where we pretend to demonstrate the increasing scope that International Human Rights Law possess.

PALABRAS CLAVE: justicia constitucional, jurisprudencia de los tribunales, derechos humanos, derecho internacional de los derechos humanos.

KEY WORDS: Constitutional Justice, case law, human rights, International Human Rights Law.

\section{INTRODUCCIÓN}

En este artículo examinaré la aplicación del Derecho Internacional de los Derechos Humanos por nuestros tribunales.

\footnotetext{
* El autor es abogado; Magíster en Derecho Público por la Facultad de Derecho de la Pontificia Universidad Católica de Chile y Magíster en Investigación Jurídica por la Universidad de los Andes; profesor de Derecho Constitucional en la Universidad Católica, en la Universidad de Chile y en la Universidad de los Andes. Es Abogado Integrante, en calidad de reemplazante, del Tribunal de Cuentas de Segunda Instancia de la Contraloría General de la República; secretario de la Asociación Chilena de Derecho Constitucional, y miembro del Consejo Nacional Editorial del Centro de Estudios Constitucionales. Recibido el 21 de marzo de 2008, aprobado el 30 de abril de 2008.
} 
Abordaré el asunto ${ }^{1}$ desde un doble ángulo. Por una parte, recordando cinco casos en que el Tribunal Constitucional ha tenido oportunidad de referirse, más o menos explícitamente, al tema de la aplicación, por esa Magistratura, de normas sobre derechos humanos, contenidas en tratados internacionales; $y$, de otra, presentando tres casos, uno resuelto por un tribunal especial y dos por los tribunales ordinarios, pero relativos a derechos de contenido económico, demostrando el alcance, cada vez mayor, que posee el Derecho Internacional de los Derechos Humanos, incluso más allá de los derechos tradicionalmente cautelados.

Finalmente, formularé algunas reflexiones a partir de aquella jurisprudencia, teniendo presente que "se llegó a una conciencia generalizada que el respeto, promoción y garantía de los derechos humanos no era una cuestión que sólo debía quedar entregada a los Estados, puesto que muchas veces los que detentaban el poder utilizaban, precisamente, ese poder con el objetivo de violar tales derechos. 'Desde este punto de vista, podría decirse que el desarrollo del derecho internacional de los derechos humanos es, en el nivel internacional, lo que el desarrollo del constitucionalismo significó en el nivel nacional. Ambos se desarrollan con el fin de limitar efectivamente el poder de los Estados"2.

\section{Aplicación por el Tribunal Constitucional}

En primer lugar, es pertinente examinar la jurisprudencia de esta Magistratura, pues en ella se comienza a advertir un cambio, todavía no abordado directamente ni menos asentado, en torno de la aplicación de los tratados internacionales en esa sede constitucional. Para aproximarse a ese cambio, que comentaré al final, resumo al máximo cinco pronunciamientos del Tribunal.

\section{Caso Almeyda}

En este primer asunto, se solicitó, invocando el artículo $8^{\circ}$ de la Constitución en su texto original, que se declarara la responsabilidad de Clodomiro

\footnotetext{
${ }^{1}$ Sobre la jurisprudencia del Tribunal Constitucional, en general, respecto de los tratados internacionales, léanse los trabajos de la profesora Marisol Peña Torres. 2007. "Los tratados internacionales en la jurisprudencia constitucional”, Estudios Constitucionales, Año 1 No 1, 2007, Santiago, Centro de Estudios Constitucionales de la Universidad de Talca, 2003, pp. 593-611; y 2007. "Cuatros estudios de justicia constitucional", Cuadernos del Tribunal Constitucional, Número 36, Santiago, pp. 56-72.

${ }^{2}$ GonZÁlez, Felipe, 1989, "Los derechos humanos como criterio de legitimidad del orden jurídico interno", Cuadernos de Análisis Jurídico, No 10, Santiago, Escuela de Derecho de la Universidad Diego Portales, p. 15.
} 
Almeyda por "haber incurrido en actos que propagan doctrinas que propugnan la violencia como también en actos que propagan doctrinas que propugnan una concepción de la sociedad, del Estado o del orden jurídico de carácter totalitario, e igualmente en actos destinados a propagar doctrinas fundadas en la lucha de clases", con el objeto que se le aplicaran las sanciones constitucionales y legales correspondientes.

El afectado, precisamente, alegó en su defensa que la aludida disposición constitucional era ilegítima, "porque infringe los artículos 18 y 21 de la Declaración Universal de Derechos Humanos de 1948 y los artículos 18 y 25 del Pacto Internacional de Derechos Civiles y Políticos de 1966, instrumentos ratificados por Chile los cuales, según el requerido, están incorporados en el ordenamiento jurídico nacional"s.

Para resolver aquella alegación, sin embargo, el Tribunal sostuvo que no era necesario formular variadas disquisiciones, ya que el objeto perseguido por el requerido, la ilegitimidad del artículo $8^{\circ}$ de la Constitución por una supuesta contradicción con las normas referidas de Derecho Internacional, resultaba improcedente, habida consideración de que, de existir tal conflicto, él debería ser resuelto, siguiendo -según se expresa en el fallo- a KELSEN, sobre la base del Derecho Nacional correspondiente, esto es, en el caso en estudio, de acuerdo con la Constitución.

Siguiendo este razonamiento, entonces, el Tribunal sostuvo que, de conformidad con la Carta Fundamental, "las normas constitucionales, en el orden interno, prevalecen sobre las disposiciones contenidas en los tratados internacionales" ${ }^{4}$, pues "la interpretación contraria significaría permitir la reforma de la Carta Fundamental por un modo distinto del establecido en sus artículos 116 al 118 (hoy, artículos 127 a 129). De allí que dicha prevalencia, tanto en la doctrina nacional como extranjera, sea la generalmente aceptada, salvo en aquellos casos excepcionalísimos en que la propia preceptiva constitucional respectiva establezca lo contrario"s.

\section{Corte Penal Internacional}

En el segundo caso, consistente con el anterior, se declaró la inconstitucionalidad del Estatuto de Roma, argumentando, también, sobre la base del concepto o principio de jerarquía, sosteniendo que la de los tratados es igual a la de la ley, aunque ellos versen sobre derechos humanos.

\footnotetext{
${ }^{3}$ Considerando $25^{\circ}$ de la sentencia pronunciada el 21 de diciembre de 1987, Rol No 46 .

${ }^{4}$ Considerando $27^{\circ}$.

${ }^{5}$ Considerando $28^{\circ}$.
} 
Es así como, en la sentencia aludida, el Tribunal abrió un párrafo especial dedicado a "la jerarquía de los tratados", en el cual comienza advirtiendo que, a raíz de la reforma introducida al artículo $5^{\circ}$ inciso $2^{\circ}$ de la Constitución, en 1989, “(...) la nueva redacción ha llevado a algunos a pretender que los tratados sobre derechos humanos tendrían rango constitucional, de manera que podrían modificar disposiciones de la Carta Fundamental"6.

Sin embargo, el Tribunal sostiene que "(...) aunque aparezca obvio, la norma constitucional reformada no consagró que los tratados internacionales sobre derechos esenciales tuvieran una jerarquía igual o superior a la Ley Fundamental"7, especialmente, teniendo en consideración la historia fidedigna de la reforma constitucional aludida.

Resulta útil recordar la paradoja de que daba cuenta el voto de minoría en aquella misma sentencia:

“¿Frente al tenor categórico de esta cláusula, podría el intérprete sostener que son contrarias a la Constitución disposiciones contenidas en el Tratado de Roma que posibilitan la intervención de una Corte Penal Internacional que permita el castigo efectivo de quienes han atropellado 'derechos esenciales que emanan de la naturaleza humana’? ¿En otras palabras, es concebible que la Constitución, por una parte, imponga a todos los órganos del Estado el deber de respetar y promover los derechos esenciales que emanan de la naturaleza humana y, por otro lado, ella misma considere que mecanismos dirigidos, inequívocamente, a cumplir su mandato y obtener el respeto que ella exige, sean declarados inconstitucionales?”.

\section{Cotizaciones Previsionales}

Avanzando, ahora, a un caso pronunciado recientemente, sobre la base de las nuevas competencias del Tribunal, especialmente en sede de inaplicabilidad, traigo a colación las sentencias pronunciadas el 24 de abril de 2007, Rol No 576, y el 5 de junio de 2007, Rol No 519.

Se trata de dos recursos de inaplicabilidad deducidos respecto de los artículos $3^{\circ}$-en un caso-, 12 y 14 -en los dos- de la Ley No 17.322 sobre cobranza judicial de imposiciones, con la finalidad de impugnarlos porque, al autorizar al juez para decretar el arresto del empleador que no consigne las sumas descontadas o que debió descontar de la remuneración de sus trabajadores y sus reajustes e intereses penales, dentro del término de quince días contado desde la fecha del requerimiento de

\footnotetext{
${ }^{6}$ Considerando $60^{\circ}$ de la sentencia pronunciada el 8 de abril de 2002, Rol No 346 .

${ }^{7}$ Considerando $62^{\circ}$.

${ }^{8}$ Considerando $9^{\circ}$ del voto de minoría.
} 
pago, si no opuso excepciones, o desde la fecha de la notificación de la sentencia de primera instancia que niegue lugar a ellas, establecería una prisión por deudas, lo cual vulnera la Constitución y el Pacto de San José de Costa Rica.

Más aún, cuando los preceptos objetados permiten que, en caso que el empleador sea una persona jurídica de derecho privado, una comunidad, una sociedad o una asociación de hecho, el apremio se pueda hacer efectivo sobre sus gerentes, administradores o respecto del presidente.

Examinando aquellas disposiciones, frente a la objeción planteada en los recursos, en cuanto a que contemplan una prisión por deudas, la cual es prohibida por tratados internacionales vigentes en Chile, el Tribunal expone que, al contrario, el precepto legal en cuestión se encuentra en armonía con los deberes impuestos al Estado en materia de derechos esenciales que emanan de la naturaleza humana, tal como lo ordena el artículo $5^{\circ}$ inciso $2^{\circ}$ de la Constitución, particularmente respecto de diversos tratados internacionales que prohíben la denominada prisión por deudas, con lo cual, evidentemente, el Tribunal acude al tratado como parámetro de control, en este caso, para sostener que la norma objetada no pugna con él.

"En efecto -prosigue la Magistratura-, el artículo 11 del Pacto Internacional de Derechos Civiles y Políticos establece que "nadie será encarcelado por el solo hecho de no poder cumplir una obligación contractual", esto es, una deuda emanada de un contrato puramente civil. Sobre el punto, la doctrina ha señalado que esto significa que la privación de libertad basada en el incumplimiento de obligaciones legales, sean de derecho privado o público, es aceptable. De modo que cuando un tribunal impone la privación de libertad para compeler al cumplimiento de una obligación legal ello no importa una vulneración de la prohibición de la prisión por deudas (...). De esta forma, se ha concluido que las obligaciones contractuales a que suelen aludir los pactos internacionales dicen más bien relación con obligaciones civiles emanadas típicamente del derecho privado, que de aquellas establecidas por la ley (...). En el mismo sentido, el Tribunal Constitucional español ha sentenciado que 'sólo puede hablarse con propiedad de prisión por deudas cuando la insolvencia tiene su base en el incumplimiento de una obligación contractual (...)".

Coherente con lo anterior, el Tribunal alude a que "la Declaración Americana de Derechos Humanos, antecedente directo del Pacto de San José de Costa Rica, en su artículo 25, inciso segundo, prohíbe la detención "por incumplimiento de obligaciones de carácter netamente civil”. Precisamente por lo mismo, el Convenio Europeo para la Protección de los Derechos Humanos y las Libertades Fundamentales admite la posibilidad de la detención o privación de libertad en su artículo

${ }^{9}$ Considerando $25^{\circ}$. 
$5^{\circ}$ 'por desobediencia a una orden judicial o para asegurar el cumplimiento de una obligación establecida en la ley"' "10.

Sobre esa base, se concluye que "los más importantes tratados internacionales de derechos humanos, en concordancia con el mandato constitucional establecido en el artículo 19 No 7o de la Constitución, tuvieron especial preocupación por la libertad de las personas frente a los abusos en que pudiere incurrir el Estado mediante detenciones ilegales o arbitrarias, esto es, que no obedecieran al quebrantamiento de un mandato legal y a una causa debidamente justificada en la razón y la equidad. En esta misma línea, proscribieron la privación de la libertad por deudas, entendiendo por tales aquellas que tuvieran como antecedente el mero interés pecuniario de un individuo ("una obligación contractual u 'obligaciones de carácter netamente civil), de modo de no poner al servicio de causas únicamente particulares o privadas el aparato represivo del Estado. De este modo se ha aceptado la privación de libertad frente al grave incumplimiento de determinados deberes legales en la medida que estuviere envuelto el interés social y el buen funcionamiento de la comunidad, en otras palabras, el bien común, que constituye el fin que debe perseguir el Estado, tal como lo reconoce el artículo $1^{\circ}$ de nuestra Carta Fundamental" ${ }^{11}$.

Por ello, en el considerando 28, se agrega que "la discusión en torno al establecimiento de la disposición (el artículo $7^{\circ}$ No $7^{\circ}$ del Pacto de San José) en particular las observaciones de los países participantes en la Conferencia Especializada Interamericana sobre Derechos Humanos celebrada en San José de Costa Rica en noviembre de 1969, permite sostener que su finalidad se vincula con la proscripción de la privación de libertad derivada de deudas propiamente civiles $y$, en modo alguno, con el incumplimiento de las obligaciones legales que involucran intereses de toda la sociedad".

\section{Responsabilidad penal adolescente}

Finalmente, la cuarta sentencia es la pronunciada el 13 de junio de 2007, Rol No 786, que resuelve un requerimiento formulado respecto de una norma impugnada del proyecto modificatorio de la Ley No 20.084, que establece, como única sanción posible para el tramo de penalidad superior a 5 años, en el caso de la responsabilidad penal de los adolescentes, la de internación en régimen cerrado, lo cual, a juicio de los requirentes, configuraría una violación al artículo $5^{\circ}$ inciso $2^{\circ}$ de la Carta Fundamental, porque el legislador no habría respetado, entre otros preceptos, el principio del interés superior del niño, consagrado en el artículo 3.1

${ }^{10}$ Considerando $26^{\circ}$.

${ }^{11}$ Considerando $27^{\circ}$. 
de la Convención sobre los Derechos del Niño, así como en sus artículos 37, 40 y 41, según los cuales la privación de libertad de los adolescentes debe ser la última ratio e imponerse por el menor tiempo posible.

El Tribunal desecha esa objeción, "pues no se divisa cómo una indicación parlamentaria destinada a eliminar la opción del juez de aplicar la internación en régimen semicerrado para aquellos adolescentes condenados por delitos que merezcan penas superiores a 5 años de privación de libertad, al menos durante los dos primeros años de la condena, pueda implicar una vulneración al inciso segundo del artículo $5^{\circ}$ de la Carta Fundamental", según se lee en el considerando $28^{\circ}$ y prosigue aclarando que "ya se ha recordado de qué manera la protección de los derechos de los adolescentes se ha encontrado especialmente presente en la gestación y desarrollo de toda la legislación sobre responsabilidad penal en que ellos puedan incurrir, la que, sin duda, ha tenido presente que, de conformidad con el artículo 37 letra b) de la Convención sobre los Derechos del Niño, no prohíbe la privación de libertad de los adolescentes, sino que impide que ella sea ilegal o arbitraria, exigiendo también que sólo proceda conforme a la ley y en carácter de último recurso, por el período más breve posible, a juicio del mismo legislador".

Útil es recordar, en este caso, la prevención del Ministro Correa Sutil quien, para concurrir al rechazo de la inconstitucionalidad de fondo planteada, formula diversas argumentaciones en torno del respeto, por parte de la norma objetada, de la Convención sobre Derechos del Niño y otras normas de Derecho Internacional, para concluir que "no verificándose contradicciones evidentes entre el precepto impugnado y las normas y principios de derecho internacional invocados, resulta inoficioso dilucidar si la eventual contradicción, que en la especie no existe, conllevaría un problema de constitucionalidad como el alegado, en virtud de la jerarquía constitucional que se pretende tengan las normas de derecho internacional de derechos humanos".

Con todo, igualmente necesario es mencionar el voto en contra del Ministro Vodanovic Schnake, quien estuvo por acoger el requerimiento en atención a que, a su juicio, la norma impugnada vulneraba la Convención de los Derechos del Niño, sosteniendo "que puede concluirse que las normas invocadas, en la medida que materializan derechos que son esenciales, son parte del parámetro de control de constitucionalidad aplicable en esta causa y, además, constituyen límites al ejercicio del poder soberano por parte de los órganos del Estado, en particular del legislador al ejercer su potestad de fijar penas".

\section{Medidas alternativas}

Muy recientemente, el 4 de octubre de este año, el Tribunal pronunció la sentencia recaída en el Rol No 807, donde examinó la constitucionalidad de 
los artículos 17 letra d) y 19 de la Ley No 18.216, que "Establece medidas que indica como alternativas a las penas privativas o restrictivas de libertad y deroga disposiciones que señala”.

El Tribunal explica, en el considerando $9^{\circ}$ del fallo:

"Que, como ha quedado descrito en la parte expositiva y en el considerando Primero que antecede, el requirente alega que el resultado contrario a la Carta Fundamental se produciría por vulnerarse la prohibición de prisión por deudas, que se encuentra establecida en el artículo 7.7 de la Convención Americana de Derechos Humanos o Pacto de San José de Costa Rica y en el artículo 11 del Pacto Internacional de Derechos Civiles y Políticos, mandatos que, según alega, se refieren a todo tipo de deudas y no sólo a las de carácter contractual, y que, además, deben ser aplicados en Chile como si fuesen de rango constitucional, en virtud de lo dispuesto en el inciso segundo del artículo $5^{\circ} \mathrm{de}$ la Constitución Política. El Ministerio Público, por su parte, señala que, cualquiera fuera la jerarquía que quiera dársele a la norma de rango internacional invocada, esta Magistratura sólo está llamada, conforme a su competencia, establecida en la Ley Fundamental, a inaplicar un precepto cuya aplicación resulte contraria a la Constitución y no a un tratado internacional. Alega, además, que no existe la pretendida contradicción".

Pues bien, frente a esa argumentación, la magistratura constitucional sostuvo, en el considerando $10^{\circ}$ :

"Que, como puede apreciarse de las alegaciones de las partes resumidas en el considerando anterior, para acoger la acción interpuesta resultaría necesario que se verificara una doble condición: en primer lugar, que existiera contradicción entre el articulo 19 de la Ley $N^{\circ} 18.216$-o más precisamente entre los efectos que produciría la aplicación de ese precepto en la gestión pendiente- y alguna de las normas de derecho internacional invocadas, y que, además, y en segundo lugar, en virtud de lo establecido en el artículo $5^{\circ}$, inciso segundo, de la Carta Fundamental, tal contradicción habilitara a esta Magistratura para declarar inaplicable el precepto legal'.

No diviso si alcanzo a comprender cabalmente lo decidido por el Tribunal, pero me pregunto si quiere decir que no basta con que se infrinja un tratado, sino que siempre se requiere de la vulneración, además, de la Constitución para pronunciar la respectiva inaplicabilidad; o, más flexiblemente entendido, que la vulneración de un tratado, constatada en dicha sede, implica quebrantar el artículo $5^{\circ}$ inciso $2^{\circ}$, con lo cual está cumplida la condición de que, también, se haya lesionado la Carta Fundamental.

Parece avanzarse en este segundo sentido, pues, en el considerando $18^{\circ}$, que, en todo caso, no fue compartido, según se previene en el fallo, por la Ministra Marisol Peña, se aclara:

"Que, no advirtiéndose contradicción alguna entre los efectos que produciría la aplicación de los preceptos legales impugnados y la norma de derecho internacional 
que se alega infringida, resulta inoficioso, un ejercicio puramente teórico, impropio de un Tribunal e inconducente para resolver el libelo, razonar acerca de si una eventual contradicción, que en este caso no se verifica, sería suficiente para inaplicar el precepto legal. En consecuencia, esta Magistratura no decidirá en esta causa si, a virtud de lo dispuesto en el inciso segundo del artículo $5^{\circ}$ de la Constitución, el derecho a no sufrir prisión por deudas es uno fundamental que emana de la naturaleza humana y si, por estar contenido en un tratado internacional ratificado por Chile y que se encuentra vigente, es o no apto y suficiente para servir de fundamento para declarar inaplicable un precepto legal".

En todo caso, me parece indudable que, con este pronunciamiento, los tratados internacionales sobre derechos humanos forman parte del parámetro de control de constitucionalidad a cargo del Tribunal.

\section{APLICACIÓN POR LOS TRIBUNALES ESPECIALES Y ORDINARIOS}

En segundo lugar, y antes de formular algunos comentarios respecto de la jurisprudencia que he recordado del Tribunal Constitucional, quisiera exponer tres casos cuyo conocimiento ha correspondido, dos de ellos, en definitiva a la Corte Suprema y el tercero al Tribunal de Defensa de la Libre Competencia, con el objeto de mostrar cómo el tema de la aplicación de los tratados internacionales sobre derechos humanos no se reduce a los derechos que podríamos denominar más tradicionales en esta materia, sino que comienza a avanzar también hacia otros más nuevos, como son los de contenido económico.

\section{Evolución jurisprudencial}

Naturalmente, resulta útil recordar que, en el ámbito de los derechos de contenido económico, inicialmente nuestros Tribunales también sostuvieron la homologación de los tratados a la ley y, por ende, sujetaron aquellas convenciones internacionales a las reglas de interpretación y aplicación de los preceptos legales ${ }^{12}$.

Así, en el caso Godoy y otros con Fisco, en 1915, la Corte Suprema declaró:

"Que esta estructura jurídica de los tratados internacionales y principalmente la exigencia constitucional de que intervengan en su aprobación los cuerpos legislativos, hace que sean ellos verdaderas leyes ya que en su génesis, desarrollo y promulgación oficial se reúnen todos y cada uno de los elementos constitutivos de una ley, tal como lo define el artículo $1^{\circ}$ del Código Civil”'

\footnotetext{
${ }^{12}$ Sobre este tema, profundícese en la excelente tesis de Henríquez Viñas, Miriam, Interpretación del artículo $5^{\circ}$ inciso $2^{\circ}$ de la Constitución Política de Chile, Santiago, Facultad de Derecho de la Pontificia Universidad Católica de Chile, 2001.

${ }^{13}$ XII Revista de Derecho y Jurisprudencia 2a p. S. 1a, p. 104.
} 
Aquella doctrina llevó a la misma Corte, en 1932, a propósito del asunto Duncan Fox con Dirección de Impuestos Internos a sostener que una ley interna posterior derogaba la norma de un tratado, puesto que:

“(...) si la sentencia que nos ocupa fuera contraria a dicho Tratado, no sería aquella la que lo desconocería sino la ley posterior que lo modificó y a la cual se amolda la resolución impugnada" ${ }^{14}$.

Sin embargo, ya en 1966, en el caso Ford Motor, la Corte Suprema entendió que:

“(...) el tratado no puede ser desconocido por la decisión unilateral del Estado contratante (...) que es el Estado de Chile, que bajo su honor, y con la expresión de su voluntad manifestada legalmente por sus personeros, garantiza a los nacionales y extranjeros que los derechos de beneficio que se adquieren (...) serán respetados (...).

No es posible admitir que el Estado chileno después de comprometer públicamente su garantía, desconozca los beneficios que otorgó (...) porque este convenio o convención legal que celebra (...) constituye un contrato que debe ser cumplido de buena fe" ${ }^{15}$.

En el año 1972, a propósito de los beneficios concedidos por la Convención sobre el ejercicio de las profesiones liberales, la Corte Suprema fue todavía más categórica en el sentido expuesto, al sostener que:

“(...) es inaceptable en Derecho que un tratado internacional pueda ser modificado por un acto unilateral de uno de los contratantes" ${ }^{16}$.

Empero, en 1984, en el caso Galletué con Fisco, la Corte Suprema volvió a su posición más antigua, al sostener que los tratados se asimilaban a las leyes ${ }^{17}$.

Pero, en 1988, en el caso Compañía Molinera San Cristóbal con Servicio de Impuestos Internos, resolvió:

"Que el Acuerdo General sobre Aranceles Aduaneros y Comercio, GATT, suscrito por Chile durante la Conferencia de Comercio y Empleo de las Naciones Unidas, celebrado en Ginebra, entre los meses de abril y octubre de 1947, se encuentra vigente en Chile desde marzo de 1979 y en virtud de lo dispuesto en el artículo $27^{\circ}$ de la Convención de Viena sobre el Derecho de los Tratados también vigente en este país se aplica con preferencia al Derecho Interno. Por otra parte, siendo un tratado un acto

${ }^{14}$ XXX Revista de Derecho y Jurisprudencia 2a p., S. 1a, p. 106.

${ }^{15}$ LXIII Revista de Derecho y Jurisprudencia 2a p., S. 1a, pp. 359-360.

${ }^{16}$ Citado por Benadava, Santiago, "Las relaciones entre Derecho Internacionaly Derecho Interno ante los Tribunales Chilenos" Nuevos enfoques del Derecho Internacional, Santiago, Ed. Jurídica de Chile, 1992, p. 55.

${ }^{17}$ Sentencia pronunciada el 7 de agosto de 1984, LXXXI Revista de Derecho y Jurisprudencia S 5a , No 3, 1984. 
bilateral, es inaceptable que pueda ser modificado por una ley interna dictada en uno de los países contratantes, acto unilateral de una sola de las partes, como es el caso de la Ley No 18.211, que, en consecuencia, no puede aplicarse a las importaciones de productos desde los países que suscribieron el citado Acuerdo del GATT (...)" ${ }^{18}$.

\section{Libre competencia}

Menciono, en primer lugar, la Resolución No 134, pronunciada por la Comisión Antimonopolio, hoy Tribunal de Defensa de la Libre Competencia, el 26 de octubre de 1982, atendido que en esa causa se examinó una denuncia sobre un posible dumping en que habría incurrido la firma Indugas S.A., al efectuar la importación de ciertos productos.

Para pronunciarse acerca de la denuncia que, en definitiva, sería rechazada, la Comisión tuvo en consideración que en Chile, al menos en esa época, no existía norma jurídica que regulara la figura del dumping, salvo el Decreto Supremo No 742, de 1981, del Ministerio de Hacienda, y el Reglamento del Acuerdo No 1411-04-811111 aprobado por el Banco Central mediante Circular No 3529, de 1981, las que habían sido dictadas con una finalidad distinta, consistente en otorgar derechos compensatorios por la importación de bienes subvencionados en su país de origen.

Sin embargo, la Comisión concluye que la legislación vigente reconoce, de una manera general, la existencia del dumping como una práctica comercial restrictiva de la libre competencia, entre otras razones, porque "(...) el Acuerdo General sobre Aranceles y Comercio (Acuerdo GATT) del año 1979, suscrito y aprobado por Chile, según Decretos Leyes No 3.566 y 3.567, de 1980, y cuya promulgación se efectuó por Decreto Supremo No 300, de 13 de junio de 1981, del Ministerio de Relaciones Exteriores, hace referencia, en su artículo $6^{\circ}$, al dumping, al expresar que éste tiene lugar cuando se permite la introducción de los productos de un país en el mercado de otro país a un precio inferior a su valor normal, lo que sería condenable cuando causa o amenaza causar un perjuicio importante a la producción nacional. Para estos efectos dicha disposición prevé en qué circunstancias un precio es inferior a su valor normal"19.

\section{Caso impuesto al lujo}

En este conocido caso, a través de un recurso de protección se planteó la vulneración del derecho de propiedad, asegurado en el artículo 19 № $24^{\circ}$ de la

${ }^{18}$ LXXXV Revista de Derecho y Jurisprudencia 2a p., S. 2a, p. 12.

${ }^{19}$ Considerando $4^{\circ}$. 
Constitución, a raíz de la decisión de la autoridad aduanera en orden a exigir el pago del impuesto específico contenido en el Decreto Ley No 825, respecto de la internación de un automóvil que, a juicio del recurrente, no debía pagarlo, conforme al Tratado de Libre Comercio suscrito por nuestro país con Canadá, desde donde provenía el vehículo.

Frente a ese planteamiento, la Corte expuso:

"Que, por consiguiente, corresponde resolver si, en conformidad con el Tratado de Libre Comercio celebrado por Canadá y Chile es o no procedente aplicar a la referida importación de un vehículo fabricado en aquel país el impuesto específico que establece el artículo 46 del D.L. No 825, de 1974; y, en caso negativo, si por este motivo la entidad recurrida al imponerlo cometió un acto ilegal o arbitrario que haya vulnerado la garantía del No 24 del artículo 19 de la Constitución Política de la República.

Que de las disposiciones analizadas en los considerandos precedentes, fuerza es concluir que el impuesto que grava la importación de los bienes a que se refiere el artículo 46 del decreto ley No 825, de 1974, tiene el carácter de arancel aduanero para los efectos del Tratado de Libre Comercio convenido por Chile y Canadá, y, en consecuencia, no puede ser aplicado a la importación de esos bienes si son originarios de Canadá.

Que esta conducta ilegal de la recurrida lesiona el derecho que el recurrente tiene sobre su patrimonio por cuanto, a causa de ella, se le ha privado del bien cuya restitución reclama, lo que constituye una vulneración de la garantía constitucional del derecho de propiedad, establecida en el No 24 del artículo 19 de la Constitución Política de la República, que esta Corte está en el deber de proteger" ${ }^{20}$.

\section{Caso Código Aeronáutico}

Por último, resulta de singular interés referirse a una sentencia pronunciada, hace muy poco, el 3 de junio de este año, por la Corte Suprema, en un caso donde se discutía acerca de la vigencia del Convenio de Varsovia-La Haya, en materia de seguros, frente a lo cual la Corte sostuvo:

"Que por último y ante aquellas alegaciones del recurrente destinadas a sostener que el Convenio de Varsovia-La Haya habría sido derogado por el Código Aeronáutico, es preciso tener presente que ya en el trabajo de la Comisión Redactora de la actual Constitución Política de la República, específicamente en la Sesión No 367, de 9 de mayo de 1978, se planteó el tema de incorporar a la propia Carta Fundamental una norma expresa que consagrara en forma explícita la supremacía de los tratados frente a las leyes. 'Todos los miembros de la Comisión reconocen por cierto, y en esto la doctrina y la jurisprudencia son uniformes, que los tratados son superiores en

${ }^{20}$ Considerandos $4^{\circ}, 10^{\circ}$ y $16^{\circ}$ de la sentencia pronunciada el 1 de abril de 2003 , Rol № 375-2003. 
jerarquía que las leyes, a pesar de que los primeros están sometidos en su formación a los 'trámites de una ley". 'En consecuencia, para algunos miembros de la Comisión aparece como algo lógico y necesario establecer, una norma de rango constitucional, similar a la del artículo 55 de la Carta Fundamental francesa de 1957, que dispone que los tratados ratificados tienen, desde su publicación, una autoridad superior a la ley, bajo reserva, en todo caso de su aplicación, por la otra parte. Quienes sostienen esta posición afirman que, de otro modo, podría llegarse al absurdo de pretender que una ley ordinaria posterior derogue o modifique un tratado'.

Posteriormente, la doctrina ha sostenido que el tema de las relaciones entre normas internacionales válidamente incorporadas al derecho interno y leyes posteriores, se rigen por el principio de la aplicabilidad, ya que ni unas ni otras se condicionan en su validez.

La consecuencia de que una norma internacional no pueda afectarse en su validez por una norma interna se deriva del principio de la buena fe y del cumplimiento de los compromisos adquiridos que constituyen principios de ius cogens codificados por la Convención de Viena sobre Derecho de los Tratados y que forma parte del ordenamiento jurídico chileno, constituyendo una limitación implícita en el ordenamiento jurídico a todos los operadores jurídicos internos. De forma tal que para dejar de aplicar debidamente un tratado internacional corresponde que previamente sea denunciado conforme a las normas que regulan esta materia.

Que por lo expuesto las normas del Convenio de Varsovia-La Haya están Ilamadas a regir en el caso de autos, con las modificaciones de los protocolos 1 y 2 de Montreal, que fueron debidamente sometidos a la aprobación nacional por medio de la ratificación y publicados en el Diario Oficial; normativa de carácter internacional que cobra aplicación directamente y por ser el derecho comúnmente aceptado por los Estados en sus relaciones internacionales" ${ }^{21}$.

\section{EVALUACIÓN A MODO DE CONCLUSIÓN}

Teniendo en mente las sentencias resumidas, formulo algunas ideas en torno del tema que nos convoca esta tarde.

En primer lugar, cabe consignar que aunque el Tribunal Constitucional, cuando ha tenido que referirse a la ubicación de los tratados internacionales dentro de nuestro ordenamiento jurídico, incluso los que versan sobre derechos humanos, ha sostenido que éstos son simples leyes. Sin embargo, recientes pronunciamientos demuestran que se avanza en una línea que cabría considerarse más flexible en la materia, al menos para, sin decir expresamente lo contrario, usar los tratados como parámetro de control de constitucionalidad.

${ }^{21}$ Considerandos $6^{\circ}$ y $7^{\circ}$ de la sentencia Rol No 4394-05. 
Desde luego, ya son varios los casos en que, sin entrar directamente en ese asunto, el Tribunal no ha desechado ni ha formulado reproche acerca de que se le haya planteado la infracción de normas de tratados internacionales sobre derechos humanos, en conjunto con la vulneración de preceptos constitucionales ${ }^{22}$.

Es más, algunos de sus integrantes han avanzado más decididamente sobre el tema, v. gr., cuando el Ministro Navarro Beltrán tuvo además presente, para concurrir al rechazo de un requerimiento, en la sentencia pronunciada el 17 de noviembre de 2006, Rol No 546, "que finalmente, por aplicación de principios de carácter general, contenidos en preceptos legales y en diversos tratados internacionales, cabe solicitar por razones de equidad la reducción del monto de cuantía de una consignación en los casos en que se trate de situaciones objetivamente abusivas o que importen una situación gravosa o altamente confiscatoria. Ello, por lo demás, se enmarca en lo señalado hace ya más de medio siglo en la Declaración Universal de los Derechos Humanos, en cuanto a que "toda persona tiene derecho a un recurso efectivo ante los tribunales nacionales competentes, que la ampare contra actos que violen sus derechos fundamentales reconocidos por la Constitución o la ley" (artículo 8)"23.

Sin embargo, es igualmente claro que, hasta ahora, aquella mayor flexibilidad se manifiesta sólo cuando el precepto legal está de acuerdo tanto con la Carta Fundamental como con lo dispuesto en el tratado internacional, evitándose el Tribunal de efectuar el parangón ley-tratado cuando de él se seguiría que aquélla es contraria a éste. Así, por ejemplo, en la sentencia pronunciada el 1 de agosto de 2007, Rol No 747:

"Que lo razonado hasta aquí acerca del modo en que está consagrado el principio de tipicidad no se ve alterado por lo dispuesto en el artículo $9^{\circ}$ de la Convención Americana de Derechos Humanos o Pacto de San José de Costa Rica, aunque se considerara, como pide la requirente, como parámetro de rango constitucional (...). Como puede apreciarse del solo lenguaje de esa norma internacional, ella, al igual que la Carta Fundamental chilena, establece el principio de legalidad -y su componente de tipicidad- en materias penales. Así, se refiere a delitos, penas, condenados y delincuentes. Ello hace innecesario referirse a la jerarquía de la norma de un tratado que no se contrapone con lo establecido en la Constitución" ${ }^{24}$.

\section{Solución del conflicto}

En realidad, el problema por el que venimos discutiendo durante tanto tiempo me parece que surge a partir de una concepción limitada acerca del ordenamiento

\footnotetext{
${ }^{22}$ Por ejemplo, véase el considerando $5^{\circ}$ de la sentencia pronunciada el 19 de diciembre de 2006, Rol No 555 .

${ }^{23}$ Considerando $14^{\circ}$.

${ }^{24}$ Considerando $26^{\circ}$.
} 
jurídico, típica del Constitucionalismo del Estado, consistente en comprenderlo íntegramente conforme a la vieja pirámide de Kelsen, en circunstancias que, siendo ésa una fórmula que permite explicarlo, sólo lo logra parcialmente, pues las relaciones que pueden producirse entre las normas que lo integran no son sólo de subordinación y de coordinación.

En efecto, en la concepción kelseniana, por cierto, las normas sólo se originan en el Estado, ente monopólico en la producción de preceptos jurídicos y, en caso de conflicto entre ellas, éste se resuelve conforme al principio de jerarquía, cuando se trata de normas situadas en distintos escalones de la pirámide, o de acuerdo a criterios clásicos de interpretación, si es que están en conflictos disposiciones que tienen el mismo nivel, v. gr., la norma posterior deroga la anterior o la especial prima por sobre la general.

Todo aquello sigue siendo válido, pero no es suficiente, cuando las relaciones que surgen entre las normas no responden a los dos únicos criterios que admite la pirámide -subordinación y coordinación-, sino que surgen otras formas de relación que exigen resolver los conflictos entre las normas de acuerdo a consideraciones diversas.

Por ejemplo, así ocurre, si es que admitimos la posibilidad, cuando entran en colisión dos derechos fundamentales, pues a pesar de hallarse ambas normas en el mismo peldaño de la pirámide, no es susceptible de resolver conforme a las reglas aludidas. En todo caso, es cierto que ese enfrentamiento puede intentar solucionarse de acuerdo a una de las fórmulas tradicionales, como es la jerarquía entre esos derechos, pero también es posible hacerlo acudiendo a la ponderación que persigue resolver el asunto a partir de la idea de que entre esos derechos no hay jerarquía.

Así también sucede, v. gr., cuando el conflicto sobreviene, en un plano totalmente distinto, entre dos cláusulas contractuales, pues allí es el propio Código Civil, en sus artículos 1560 a 1566, quien provee reglas o técnicas especiales de solución de esa controversia, para cuya adecuada solución no bastan los criterios kelsenianos.

En fin, así sucede igualmente cuando la pugna sobreviene entre una norma de un tratado internacional y otra de Derecho Interno, en que las fórmulas que derivan de la estructura piramidal del ordenamiento jurídico no admiten una solución que sea siempre respetuosa de la convención o acuerdo que importa todo tratado internacional. Esta es la base del reconocimiento que ha efectuado nuestra propia Constitución, tras la reforma introducida, en agosto de 2005 por la Ley No 20.050, al artículo $54 \mathrm{~N}^{\circ} 1^{\circ}$ de la Carta Fundamental, al disponer que los tratados internacionales sólo pueden ser derogados, modificados o suspendidos conforme a las normas previstas en el propio tratado o de acuerdo a las normas generales de Derecho Internacional, pero no por decisiones internas unilateralmente adoptadas. 
Por ende, los conflictos entre el Derecho Internacional de los Derechos Humanos -contenido en tratados o en normas de ius cogens- y el Derecho Interno requieren soluciones que escapan a la concepción clásica que visualiza el ordenamiento jurídico sólo como una pirámide.

Y debe sostenerse que, en todo caso, no siempre la solución es unívoca, pues conservar la intangibilidad del acuerdo internacional no puede conducir a un resultado lesivo de los derechos fundamentales, ya que, entonces, se impone la potestad estatal -que origina el tratado, propia de un Constitucionalismo ya superado-por sobre los derechos, lo cual resulta inaceptable para el Constitucionalismo Humanista -que excluye el monopolio en la interpretación de la Carta Fundamental y en la defensa de los derechos-, ya que, como nos recuerda MARTínez EstaY, aludiendo a los casos Solange Iy Maastricht, pronunciados por el Tribunal Constitucional alemán, el primero de ellos “(...) reivindica la competencia del Tribunal para proteger los derechos fundamentales de los alemanes, lo que incluía la posibilidad de revisar un reglamento de la Comunidad Europea con la Constitución alemana. Por su parte (...) (en la segunda sentencia) el Tribunal Constitucional alemán sostuvo que el Derecho de la Unión Europea debe ajustarse a la Constitución alemana y por ello el Tribunal es competente para controlar que esto sea efectivamente asî" 25 .

\section{Bloque de constitucionalidad}

Cuestión distinta y que merece también ser analizada, es preguntarse si las normas contenidas en tratados internacionales, que versan sobre derechos humanos, integran el parámetro de control que debe considerar el Tribunal Constitucional al ejercer las atribuciones que le confiere el artículo 93 de la Carta Fundamental.

Desde luego, me parece que de ello no hay duda, sobre la base de la noción del bloque de constitucionalidad que, en nuestro Derecho tiene acogida expresa, desde 1989, en el artículo $5^{\circ}$ inciso $2^{\circ}$ que le impone a dicha Magistratura $-y$ a todo órgano estatal- el deber de respetar y promover esos derechos contenidos en los tratados a la par que los garantizados en la Constitución.

En este sentido, el profesor Nogueira define ese bloque como "el conjunto de los derechos de la persona (atributos) asegurados por fuente constitucional o por fuentes del derecho internacional de los derechos humanos (tanto el derecho convencional como el derecho consuetudinario y los principios de ius cogens) y los derechos implícitos, expresamente incorporados a nuestro ordenamiento jurídico por vía del artículo 29 literal c) de la Convención Americana de Derechos Humanos, todos los cuales, en el ordenamiento constitucional chileno, constituyen

${ }^{25}$ Martínez Estay, José Ignacio, Introducción del Derecho y a las instituciones de la Unión Europea, Santiago, Ed. Jurídica de Chile, 2007, pp. 103-104. 
límites a la soberanía, como lo especifica categóricamente el artículo $5^{\circ}$ inciso segundo de la Constitución chilena vigente" ${ }^{26}$.

Incluso más, el Tribunal ha ido más allá, pues ha ejercido su competencia -en sede de inaplicabilidad-configurando un nuevo derecho esencial, no contemplado expresamente en el catálogo de la Constitución y los tratados vigentes en nuestro país, como es el derecho de acceso a información pública ${ }^{27}$.

¿Cómo podría sostenerse, entonces, que, en cumplimiento del mandato impuesto por el aludido artículo $5^{\circ}$ inciso $2^{\circ}$, el Tribunal pueda ejercer sus potestades de control sobre la base de un derecho esencial no previsto en el Derecho Positivo y que no pueda hacerlo considerando un derecho de esa naturaleza que sí está reconocido, aunque sea en un tratado internacional o con el carácter de ius cogens?

En fin, las sentencias revisadas, pronunciadas en sede de libre competencia o por la Justicia Ordinaria, muestran cómo el tema no tiene relevancia sólo respecto de los derechos tradicionalmente vinculados al Derecho Internacional de los Derechos Humanos, sino que se expande a todos los derechos que hoy consideramos fundamentales.

\section{BiBLIOGRAFÍA}

Benadava, Santiago, "Las relaciones entre Derecho Internacional y Derecho Interno ante los Tribunales Chilenos"Nuevos enfoques del Derecho Internacional, Santiago, Ed. Jurídica de Chile, 1992.

GONZÁLEZ, Felipe, "Los derechos humanos como criterio de legitimidad del orden jurídico interno", Cuadernos de Análisis Jurídico No 10, Santiago, Escuela de Derecho de la Universidad Diego Portales, 1989.

Martínez Estay, José Ignacio, Introducción del Derecho y a las instituciones de la Unión Europea, Santiago, Ed. Jurídica de Chile, 2007.

Nogueira AlCalá, Humberto, Lineamientos de interpretación constitucional y del bloque constitucional de derechos, Santiago, Ed. Librotecnia, 2006.

Peña Torres, Marisol. "Los tratados internacionales en la jurisprudencia constitucional”, Estudios Constitucionales, Año 1 No 1, Santiago, Centro de Estudios Constitucionales de la Universidad de Talca, 2003, pp. 593-611.

Peña Torres, Marisol. "Cuatros estudios de justicia constitucional”, Cuadernos del Tribunal Constitucional No 36, Santiago, 2007.

\footnotetext{
${ }^{26}$ Nogueira Alcalá, Humberto, Lineamientos de interpretación constitucional y del bloque constitucional de derechos, Santiago, Ed. Librotecnia, 2006, pp. 244-245.

${ }^{27}$ Léase la sentencia pronunciada el 9 de agosto de 2007, Rol No 634.
} 


\section{REVISTAS JURÍDICAS}

XII Revista de Derecho y Jurisprudencia 2a p., S. 1a, p. 104.

XXX Revista de Derecho y Jurisprudencia 2a p., S. 1a , p. 106.

LXIII Revista de Derecho y Jurisprudencia 2a p., S. 1ª, pp. 359-360

LXXXI Revista de Derecho y Jurisprudencia S. 5a , No 3.

LXXXV Revista de Derecho y Jurisprudencia 2a p., S. 2a, p. 12 